\title{
Editorial: A Message from the Editor
}

Assalaamu Alaykum

Dear IMANA Members,

The executive council of IMANA asked me to resume the editorship of JIMA. I could not refuse because I always believed it to be a vital organ of our beloved IMANA. I hated to see that it ceased publication.

I accepted the position knowing very well that enormous effort is needed to reestablish it as a viable journal.

The Executive Council, under the leadership of Dr. Shahid Athar, the chairman of the Board of Regents, and Dr. Farooq Selod, the president, assured me of the Executive Council's support. I was fortunate that Dr. Faroque Khan and Dr. Hussain Nagamia accepted to be associate editors and help me in this endeavor.

I plan to maintain the special flavor of the journal as an "Islamic" medical journal, which distinguishes it from other medical journals.

One of the problems I encountered during my editorship of JIMA up to November 2000 was the paucity of articles submitted by our members. I am encouraged now by the fact that IMANA holds at least two conferences a year. I have attended most of these conferences and was impressed by the high quality of the presentations during the last few years. I expect those presenters to submit their manuscripts to JIMA in a timely fashion. I was also impressed by the recent infusion of "young blood" in our organization. This not only ensures the vitality and continuity of IMANA but also hopefully will translate their enthusiasm into actively supporting all activities of IMANA, including JIMA.

While we will continue to ask for original research papers, we will also consider review articles, public health articles, case reports and articles summarizing advances in a subspecialty. We are particularly interested in articles about the history of medicine, specifically Islamic medicine, the contributions of Muslim scholars and physicians, of the past as well as the present, and the activities of members that help their local communities.

We will try to devote a special section for Islamic medical ethics with both submitted articles and questions submitted by members. We will then publish the answers to these questions provided by members of the ethics committee of IMANA or Muslim scholars. As evidence of the importance of this section we are publishing in this first issue the position paper "Islamic Medical Ethics: The IMANA Perspective" produced by IMANA's ethics committee. This position paper represents the current considered opinion of the committee members, who spent a lot of time studying these questions and consulting with Muslim scholars and collating all this information into a document. At the same time, it is understandable and expected that not every IMANA member will agree with every statement in this position paper.

I would encourage all readers to comment on the position paper whether they agree or disagree with one or another statement in the form of a "letter to the editor" or with an article submission with supporting evidence. It is also obvious that this position paper did not cover many areas of concern. We will need to cover these areas. We ask our members to suggest such topics or, better still, to write articles about these topics so that they will be included when the position paper is updated, in sha' Allah.

Dear members, I accepted this responsibility knowing very well how hard and challenging it is. I expect the cooperation and help of all members, including the governing body. But above all, I ask the guidance and help of Allah as our efforts are-as they should be-directed with sincerity to serve Him in any way we can. In this case, it is the spreading of knowledge. May Allah guide our steps, accept our work and guide us to the right path.

Hossam E. Fadel, M.D.

Editor-in-chief, JIMA 